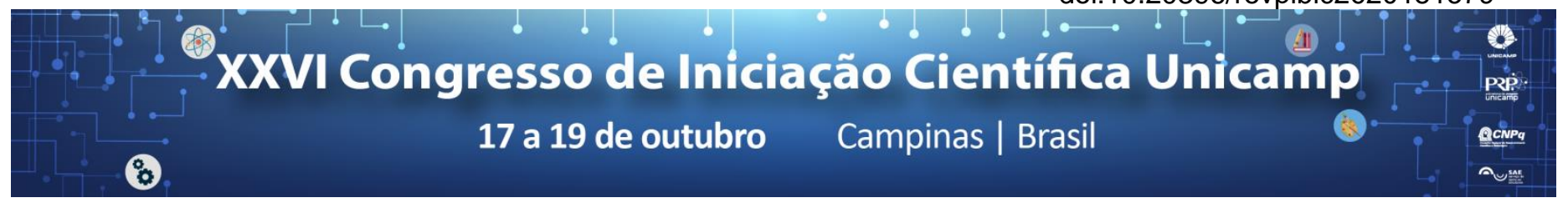

\title{
Avaliação da Atenção Primária por usuários da Saúde da Família Fluvial em comunidades ribeirinhas.
}

\section{Wellington Pereira da Silva*, Maura C. Silva Figueira, Eliete Maria Silva}

\begin{abstract}
Resumo
Objetivo: avaliar os atributos da Atenção Primária à Saúde na Estratégia Saúde da Família Fluvial (ESFF) na perspectiva de usuários ribeirinhos no município de Santarém, Pará. Método: trata-se de uma pesquisa avaliativa, transversal e quantitativa, com dados coletados por meio de entrevistas com o PCATool adultos versão reduzida com 342 participantes nas suas comunidades. As análises foram pelos softwares estatísticos SAS versão 9.4 e o Statistical Package for the Social Sciences versão 22. Resultados: o atributo com melhor avaliação foi o de Coordenação Sistema de Informações $(8,95)$ e com mais baixa foi a Orientação Comunitária $(2,51)$. Conclusão: o estudo mostra importantes desdobramentos para o arranjo assistencial de equipes de saúde da família fluvial, bem como subsidia políticas públicas para a implantação e implementação de outras formas de assistência que alcancem as populações mais vulneráveis neste contexto.
\end{abstract}

\section{Palavras-chave: \\ Atenção Primária à Saúde; Avaliação em Saúde; Estratégia Saúde da Família}

\section{Introdução}

Na Atenção Primária em Saúde (APS), de acordo com Bárbara Satrfield, existem atributos essenciais e derivados. Os essenciais são: o acesso de primeiro contato de indivíduos com os serviços de saúde; a longitudinalidade do cuidado ao longo do tempo; a integralidade, que são os diversos serviços ofertados para suprir os aspectos biopsicossociais do processo saúdedoença e a coordenação da atenção, que pressupõe a integração do cuidado. Os atributos derivados a serem considerados são: orientação familiar, comunitária; e competência cultural ${ }^{1}$.

A Estratégia Saúde da Família (ESF) visa à reorganização da atenção básica no Brasil. A ESF deve seguir as diretrizes da atenção básica e do Sistema Único de Saúde (SUS) estabelecendo vínculo entre os usuários e profissionais dos serviços de saúde e contato constante com o território ${ }^{2,3}$.

O estudo sobre a APS se faz importante para avaliar o arranjo assistencial criado pelo Ministério da Saúde para o contexto amazônico que é a ESFF, tendo em vista a dispersão populacional, diversidade geográfica e cultural destes cenários, fazendo parte da Agenda Nacional de Prioridades de Pesquisa em Saúde no Brasil (ANPPS) sub agenda - Dinâmica e compreensão dos sistemas e políticas de saúde 4 .

Nessa perspectiva, propôs-se como objetivo, avaliar os atributos da APS das Estratégias de Saúde da Família Fluviais na perspectiva de usuários ribeirinhos do município de Santarém-Pará.

\section{Resultados e Discussão}

Trata-se de uma pesquisa avaliativa, de delineamento transversal e abordagem quantitativa, tendo como campo de investigação empírica as três equipes de ESFF em suas áreas de abrangência na APS, sob responsabilidade da Secretaria Municipal de Saúde, no município de Santarém - Pará.

O estudo foi realizado no período de outubro 2017 a maio de 2018. Foi aplicado um instrumento para coleta de dados sócio-econômicos e o instrumento PrimaryCare Assessment Tool (PCATool) versão reduzida aos usuários dos serviços de saúde para avaliação da APS ${ }^{3}$.

Neste estudo foram entrevistados 342 usuários da ESFF do município. A maioria dos usuários é do sexo feminino $(79,53 \%)$, casados $(44,15 \%)$, renda familiar abaixo de um salário mínimo $(65,20 \%)$, possuem o ensino fundamental incompleto $(34,21 \%)$. O atributo com melhor avaliação foi o de Coordenação - Sistema de Informações com escore de 8,95. E o com mais baixo escore foi a orientação comunitária $(2,51)$. Os atributos que também ficaram abaixo do escore de referência $(\leq 6,6)$, ou seja, que apresentaram resultados insatisfatórios, foram:grau de afiliação com serviço de saúde $(6,08)$, coordenação - integração de cuidados $(6,08)$, integralidade - serviços disponíveis $(5,07)$ e integralidade - serviços prestados $(6,36)$.

\section{Conclusões}

Mesmo enfrentando dificuldades para proporcionar acesso a APS, como as grandes distâncias e dificuldade no acesso em alguns períodos pelas cheias e seca dos rios, o município criou maneiras de abranger a população ribeirinha que são as ESFF e as unidades em comunidades maiores e estratégicas para o acesso geográfico, para proporcionar a integralidade da assistência, fornecendo os recursos para corresponder às necessidades dos usuários. Alguns atributos da APS precisam ser melhorados para suprir as necessidades em saúde no contexto das populações ribeirinhas.

\section{Financiamento}

Financiado pelo Conselho Nacional de Desenvolvimento Científico e Tecnológico (CNPq).

\section{Referências:}

1.Starfield B. Atenção primária: equilíbrio entre necessidades de saúde, serviços tecnologia. Brasília: UNESCO, Ministério da Saúde; 2002.

2.Oliveira, MAC. Atributos essenciais da Atenção Primária e a Estratégia Saúde da Família. RevBrasEnferm. 66(esp): 158-64; 2013.

3. Brasil, Ministério da Saúde. Portaria no 2.488, de 21 de outubro de 2011. Aprova a Política Nacional de Atenção Básica, estabelecendo a revisão de diretrizes e normas para a organização da Atenção Básica, para a Estratégia Saúde da Família (ESF) e o Programa de Agentes Comunitários de Saúde (PACS). Diário Oficial, Brasília, n.204, p.55.

4.Brasil. Ministério da Saúde. Secretaria de Ciência, Tecnologia e Insumos Estratégicos Departamento de Ciência e Tecnologia.Agenda nacional de prioridades de pesquisa em saúde / Ministério da Saúde. 2. ed., Brasília: Editora do Ministério da Saúde, 2015. 